\title{
Spatial Diffusion Aspects of Marketing Strategies \#
}

\author{
Marilyn A. Brown \\ INTRODUCTION
}

This paper examines the impact of marketing strategies upon spatial patterns of innovation diffusion. Thus, it emphasizes and elaborates upon the roles of those public and private change agencies which employ various mechanisms to enable and induce adoption of innovations. It is assumed that the techniques employed to market innovations will lead to predictable spatial patterns of adoption. In particular, five marketing mechanisms are examined: the location of marketing agencies; the development of infrastructure; pricing; promotional communications; and market segmentation. These mechanisms, both individually and through their interaction, are hypothesized to significantly affect spatial point patterns of diffusion in a predictable fashion.

The paper does not examine the psychological variables which interface between the selling of an innovation and the ultimate purchase of it. Rather, it assumes that at the initiation of efforts to market an innovation, the spatial pattern of psychological resistance to the innovation is uniform across individuals whose farming activities are pertinent to use of the innovation. These individuals are called "potential adopters." This assumption is facilitated through the selection of a highly uniform study area. Thus, the paper does not adopt the traditional emphasis upon aspects of individual decision making as determinants of diffusion. Instead it seeks to illustrate that the mechanisms through which innovations are made available to potential adopters are useful in predicting spatial diffusion patterns.

The first portion of this paper summarizes the theoretical literature on the role of these five marketing mechanisms. Attention then turns to the diffusion of four agricultural innovations in a portion of Eastern Ohio. After briefly describing how each innovation was marketed, a pattern of adoption, represented as points in the plane, is hypothesized for each innovation. The hypothesized patterns are then compared with observed patterns.

\#An earlier version of this paper was published in the Ohio State University Department of Geography Studies in the Diffusion of Innovation as Discussion Paper Number 44. It was co-authored with Lawrence A. Brown and was entitled "Innovation Establishment in a Rural Setting: Four Case Studies with Reference to a Theoretical Framework." The helpful comments of L. A. Brown, Arthur Getis, and three anonymous referees are gratefully acknowledged, as is the cartographic assistance of J. Bier and S. M. Macey. 


\section{THEORETICAL CONSIDERATIONS}

Five marketing mechanisms are seen as having significant influence upon spatial aspects of diffusion. The first, the location of marketing agencies, influences the location of adopters in a number of ways. Most important, the distribution of agencies affects the availability of the innovation. Since adoption of an innovation cannot usually occur until the innovation is available, the location of marketing agencies is critical in explaining diffusion at scales larger than the local. This has been illustrated in studies of cable television in Ohio (L. A. Brown, Malecki, Gross, Shrestha, and Semple, 1974) and Montessori teaching in the U.S. (Meyer, 1975).

Similarly, at the local scale of analysis, the density and pattern of diffusion agencies in any particular area affects the location-related costs of adoption. For instance, if potential adopters are uniformly distributed and if the pattern of diffusion agencies is dense, then transport costs related to adoption will be low, and the distribution of adopters will tend to be dense and uniform.

Once a diffusion agency has been established, the marketing activities it undertakes will influence the specific role that its location plays. For instance, a second strategy involves the development of infrastructure to permit a diffusion process to be implemented, maintained, and expanded. For example, an agency may maintain delivery, collection, or service systems to facilitate adoption (L. A. Brown and Lentnek, 1973; Garst, 1975) or may establish an energy infrastructure to enable adoption of innovations such as electric appliances or telephones. Other entities may also provide such infrastructure. In the diffusion of Bank Americard among households, for instance, the utility of adoption depends upon the infrastructure of merchants willing to accept the card (M. A. Brown and L. A. Brown, 1976). Similarly, the diffusion of agricultural technology may depend upon the infrastructure of credit agencies.

In some situations, potential adopters are able to utilize an innovation only in spatial proximity to the infrastructure, as in the case of cable television (Seiling, Malecki, and L. A. Brown, 1975). In other situations, an innovation may be used anywhere, but must be serviced frequently, as in the adoption of computer equipment where access to maintenance and repair services tends to be critical. Both of these situations would be infrastructure constrained, in that the infrastructure channels the innovation's spatial diffusion. Where access to such infrastructure does not play an important role, a diffusion process is more infrastructure independent (L. A. Brown, 1975).

Pricing is a third marketing activity which may affect the spatial variation in adoption cost, and thereby affects the role of each agency's location. If an agency provides no delivery, service, or other infrastructure, it charges a uniform price at its outlet. The effect of this pricing policy on adoption depends upon the price elasticity of demand for the innovation and the degree to which potential adopters perceive accessibility to the diffusion agency as a significant cost. Ceteris paribus, if the price elasticity and access 
costs are significant, a distance decay pattern of adoption would be expected. Otherwise there would be a tendency toward a uniform distribution of adopters.

Alternatively, the marketing agency or another entity may provide some infrastructure and charge either a uniform delivered price or a distancerelated price. Uniform delivered pricing tends to equalize access costs across potential adopters within the area served by the infrastructure and therefore produces a tendency toward a uniform density of adopters within the area. By similar reasoning, distance-related pricing produces a tendency toward a distance decay pattern of adoption within the area served by the infrastructure. The extent of this pattern depends upon the delivery charges and the price elasticity of demand for the innovation.

A fourth marketing strategy employs promotional communications to provide potential adopters with information about an innovation and to persuade them to adopt. While many aspects of this may have spatial implications, the type of media through which these communications are channeled are particularly critical to the resulting pattern.

A channel of information may be personal or impersonal. The former involves a one-to-one correspondence between communicator and receiver. The message is thereby tailored to the receiver. Impersonal communications refer to all other media including mailed literature, newspaper articles, television commercials, and radio ads (Rogers, 1962; Redlich, 1953). This classification distinguishes between channels which vary in the number and spatial range of people who can be reached. Impersonal channels can reach larger numbers of people per message, and their characteristic range tends to be greater than that of personal channels (Hagerstrand, 1967, pp. 138-9). However, impersonal channels tend to be less effective than personal ones in transmitting information and thereby altering attitudes (Coleman, Katz, and Menzel, 1959; Arndt, 1967). Thus, diffusion agencies must trade-off between the effectiveness and the spatial range and density of receivers. If there is some spatial facet to the diffusion process which requires careful manipulation (e.g., attempting to confine adoption to an area near a service or delivery infrastructure), a diffusion agency will probably resort to channels which have a small spatial range such as personal selling. If the spatial pattern of diffusion is not important to an agency, it might broadcast information via the mass media. Here the object might be to reach the largest number of opinion leaders who will then persuade others to adopt.

The fifth activity involves market segmentation. This entails identification of the various subgroups of potential adopters and tailoring of the agency's promotional efforts to these subgroups. These activities may have direct or indirect spatial effects.

Direct spatial effects occur when a segmentation policy is based upon locational criteria, resulting in designated subgroups such as urbanites, suburbanites, or New Englanders. An example at a local scale is the service station, hardware, or drug store manager who differentiates between neighborhood and more distant customers, stressing promotional efforts intended for nearby households rather than for the urban area as a whole. 
These strategies tend to occur, in part, because markets are spatially limited in accordance with the order of an innovation (i.e., convenience vs. shopping vs. specialty goods) - making neighborhood residents more frequent patrons.

Indirect spatial effects occur when market segments are partitioned on the basis of socio-economic variables which have patterns in space. Submarkets such as senior citizens, black youths, and young married couples frequently exhibit distinct spatial patterns. Urban neighborhood and suburban typologies provide further evidence that promotional efforts may have indirect spatial impacts (Schwirian, 1974; M. A. Brown, 1981).

No one of these marketing variables can be considered in isolation since each tends to be affected by the others. First, diffusion agencies frequently orchestrate their actions to efficiently manipulate the diffusion process. Second, joint effects from various combinations of actions may exceed the aggregate of the individual effects.

For example, infrastructure development involves an implicit segmentation of the market by increasing the utility of adoption for those reached by the infrastructure. It therefore may affect both where promotional communications are directed and the types of channels employed. Conversely, if a particular market segment, as identified by some characteristic such as income, has distinct locational characteristics, infrastructure provision and promotional communications might reflect that. Similarly, since pricing policies affect the spatial distribution of adoption costs, they embody an implicit market selection and segmentation policy which may be reflected in the promotional communications strategy.

\section{EMPIRICAL EXAMPLES}

Two sets of empirical examples are considered. One set consists of infrastructure constrained innovations and illustrates the effects of infrastructure and pricing strategies. The second set illustrates infrastructure independent diffusion. In all, four agricultural innovations are examined for an identical four-county area in Eastern Ohio (Figure 1). A detailed description of the study area is found in M. A. Brown (1977).

\section{INFRASTRUCTURE AND PRICING EFFECTS}

The introduction of two new agricultural products, Pro-las cattle feed and custom blended fertilizer, into Eastern Ohio illustrates two infrastructure constrained diffusions with contrasting pricing policies. Pro-las (hereafter also called innovation A) is a liquified cattle feed supplement containing protein, minerals, vitamins, and molasses; custom blended fertilizer (also called B) is a mixture of chemicals blended individually to match the characteristics of a soil sample.

$A$ and B were introduced into four counties of Appalachian Ohio in 1971 by the Belmont County Farm Bureau Cooperative. This diffusion agency is a franchise agency of Landmark, Inc., the statewide umbrella organization for Ohio's farm cooperatives. The two innovations were 
distributed under monopoly conditions, in part because Ohio Farm Bureaus honor each other's trade areas.

Both A and B are dependent upon a transportation infrastructure. Pro-las is stored in a tank in the farmer's pasture and filled periodically at a frequency dependent upon the tank's size and the number of cattle using it. Four delivery routes were developed to provide this service. Each route serves one of the four counties in the Farm Bureau's market area and originates at one of two depots in Woodsfield and Bethesda (Figure 1). A uniform delivered price was established for A, thereby distributing transportation costs (per ton-mile) equally among all customers.

Innovation B is distributed from the Farm Bureau's blend plant in Quaker City, a location central to its market area (Figure 1). The farmer takes soil test results to this plant, where fertilizer is mixed from bulk supplies. The fertilizer is then either transported by the purchaser or delivered by the Farm Bureau at a fee per ton-mile. Thus, the total cost of $B$ varies according to the location of the farmer.

The different pricing policies associated with the infrastructure of $\mathrm{A}$ and $B$ resulted from differences in the cost of delivery. $A$ is a homogeneous product while B is not. B requires both stockpiles of ingredient materials and a complement of expensive mixing equipment. Thus, separate deliveries are made for each customer, enabling the individual transport costs to be charged.

These disparate pricing schemes appear to account for different market segmentation and promotional communications policies. Innovation A, with a uniform delivered price, employed personal contact between Farm Bureau employees and potential adopters located near existing or developing delivery routes. Since the Farm Bureau sequentially developed its delivery routes, the spatial segmentation of the market shifted over time. The first depot was established in Monroe County, as was the first delivery route. In 1972 and 1973 the promotional campaign was extended to Belmont County where the second depot was located. More recently Guernsey and Noble Counties have been developed with routes originating in Bethesda and Woodsfield, respectively, the original two depots.

In contrast, the Farm Bureau had little incentive to spatially segment its market for innovation B. With a uniform outlet price and a distancerelated delivered price, the spatial distribution of adopters did not affect profits associated with the innovation. Thus, the Farm Bureau vigorously promoted its product throughout the four-county market area, with no spatial bias, predominantly relying upon mass media. Ads were placed in one or more newspapers in each county, mailers were enclosed with bills to all Farm Bureau credit customers, radio advertising was undertaken, and some farmers were visited by Farm Bureau employees.

\section{INFRASTRUCTURE INDEPENDENT DIFFUSION}

The diffusions of no till farming and the Ohio Production Testing Program in the four-county study area illustrate infrastructure independent diffusion. Consequently, these diffusions contrast markedly with the 
previous ones in which both infrastructure and pricing were controlling factors. No till farming (hereafter also called innovation $\mathrm{C}$ ) is a method of planting corn and forage crops by using herbicides instead of plowing. It saves labor, reduces soil erosion, and conserves water through the weed mulch it creates. It was developed in the late 1960's and was concurrently introduced into Ohio. The Ohio Production Testing Program (hereafter called D) began in 1958 and is a service developed by the Cooperative Extension Service to provide Ohio farmers with a method of improving their livestock through selective breeding. The Cooperative Extension Service analyzes the weight, size, and other characteristics of an individual beef cow or sheep, and calculates various evaluative indices which can be used to cull herds and flocks.

The diffusion of $\mathrm{C}$ involved numerous private and public agencies, including no till planter manufacturers and dealers, herbicide manufacturers and dealers, the Cooperative Extension Service, the Soil Conservation Service, and other government agencies. Thus, the marketing agency system is complex and locationally pervasive. This contrasts with the previous studies in which only one or two nodes were important.

Innovation D principally involves only one propagator-the Cooperative Extension Service. Yet, as is true for no till farming, its network of

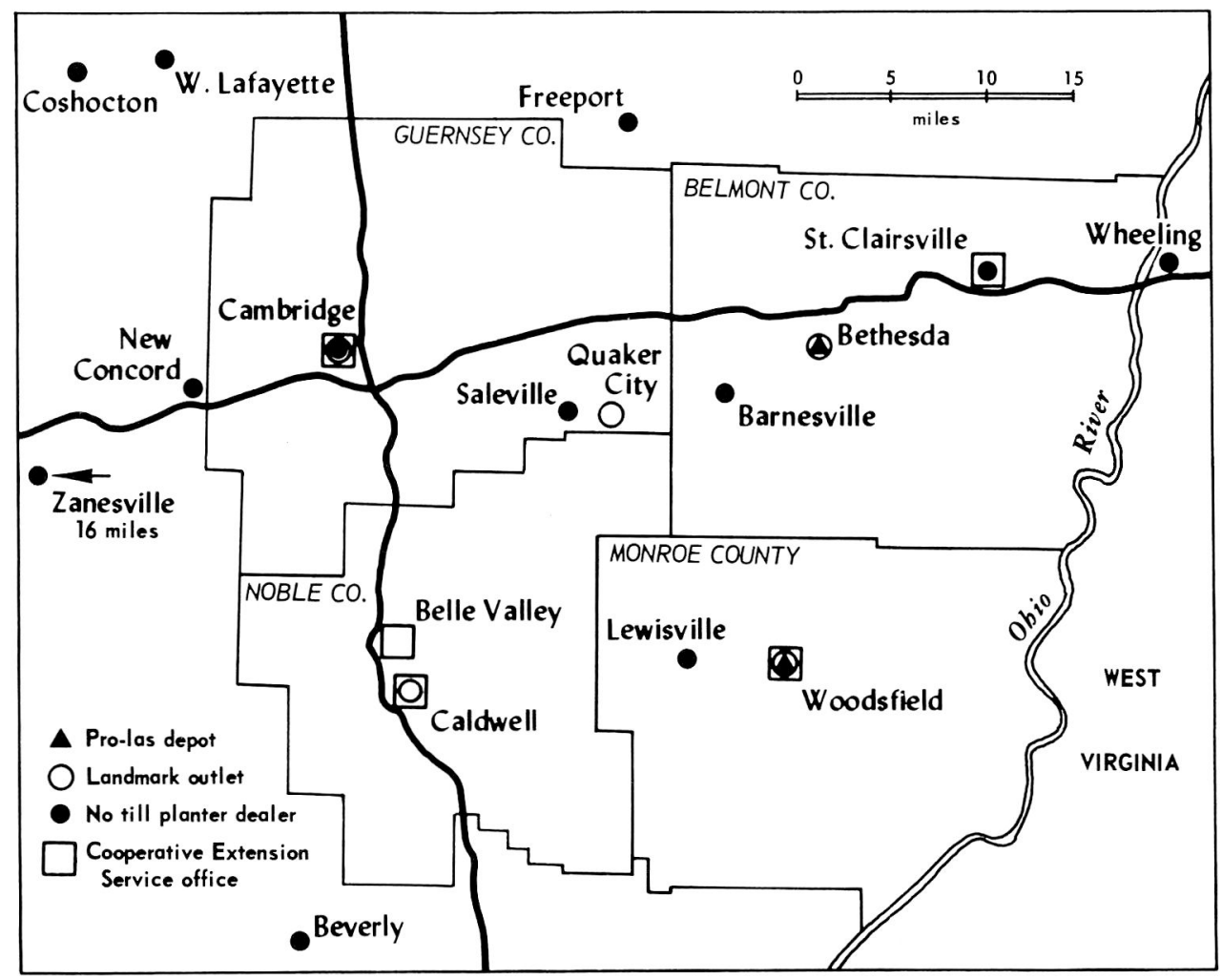

Figure 1: The Study Area 
marketing agencies is locationally pervasive. There is an Extension office in each county seat (Caldwell, Cambridge, St. Clairsville, and Woodsfield), and an additional regional office in Belle Valley. Furthermore, agents from the state Extension Service in Columbus also actively promote the program.

Both innovations have numerous nodes from which infrastructure emanates. For instance, $\mathrm{C}$ employs a no till planter and herbicides, both widely available through the many farm supply and equipment dealers in the area. A further and perhaps more important infrastructure is centered around those adopters who lease or lend their no till planters or who custom no till plant for other farmers. This infrastructure, like that for A, grows through time.

The dispersed infrastructure for production testing surround the location of scales for weighing animals, livestock grading technicians, and Extension Service agents for interpreting production testing results and recommending a course of action. Thus, the nodes include Extension Service offices, local farmers with scales, breed association offices, etc.

The spatial pricing of the "adoption package" of goods for C and D involves both uniform delivered prices and uniform prices at the outlet. Yet this is inconsequential because the outlets are effectively pervasive.

Promotional communications for $\mathrm{C}$ emanated from numerous parties, including the Cooperative Extension Service, Soil Conservation Service, and other government agencies. They employed personal contact with farmers, newsletters, local field demonstrations, and talks at various local farm meetings. Several chemical companies manufacturing no till herbicides employed media advertising and field demonstations; no till planter dealers pursued national promotional campaigns, relying heavily upon farm journal advertisement, and local dealers supplemented this exposure with local newspaper advertisements and personal contact with farm operators.

Promotional communications for D were initiated in the late 1950's and early 1960's by state Extension Service agents who promoted the program to both county agents and farmers. This was in part accomplished by mailing literature to local agents and to farm operators, publishing articles in farm magazines and journals, and talking at farm meetings. Presently, county agents play the dominant role, employing similar promotional methods. Thus, for both of these innovations there was area-wide advertising via the media, as well as local promotional efforts undertaken by dispersed nodes.

A set of hypotheses concerning the spatial patterns of diffusion of adopters is suggested by the marketing efforts undertaken to promote the innovations.

\section{THE HYPOTHESES}

The uniform delivered price for A, by itself, suggests a process of adoption in the plane similar to that of the population of potential adop- 
ters. The orchestration of promotional communications with delivery infrastructure, however, suggests the following:

Hypothesis 1: Adopters of A were initially and remain more spatially clustered than the population of potential adopters, but with decreasing clusteredness through time.

The spatial broadcasting of promotional communications for $\mathrm{B}$, by itself, suggests a process of adoption in the plane similar to that which generated the population of potential adopters. The distance-related pricing, however, causes the probability of adoption to decrease with distance from the point of distribution. Thus:

Hypothesis 2: Adopters of B were initially and remain more spatially clustered than the population of potential adopters.

The most important infrastructure for innovation $\mathrm{C}$ grows through time, as local farmers purchase no till planters and make them available to nearby farm operators through renting, borrowing, or custom planting. Since promotional communications were broadcast throughout the area and other infrastructure were effectively ubiquitous, one would expect:

Hypothesis 3: Adopters of C initially were located in a pattern similar to that of the potential adopters; they later became spatially clustered around randomly located nodes, as in a compound negative binomial process.

Since the infrastructure for $\mathrm{D}$ is spatially pervasive, and promotional communications were broadcast throughout the study area, the following is suggested:

Hypothesis 4: Adopters of $\mathrm{D}$ have been and remain located according to a spatial process similar to that generating the population of potential adopters.

\section{THE STUDY AREA AND SAMPLING DESIGN}

The research focuses upon four counties in Appalachian Ohio (Figure 1). The western boundary of the study area is approximately 75 miles east of Columbus, and the eastern edge borders on the Ohio River. Two interstate highways traverse these counties, yet the area remains predominantly rural. Its largest city, Cambridge, had fewer than 14,000 residents in 1975 , and one county contained no incorporated place with more than 2,500 inhabitants (U.S. Office of Revenue Sharing, 1976). The rural population ranges from 49.0 percent of the total population in Belmont County to 79.4 percent in Monroe County (U.S. Bureau of the Census, 1973), and in all four counties, beef and dairy cattle are the most important farming activities (U.S. Bureau of the Census, 1972). 
The data for these case studies were obtained in 1975 and comprise one sample and four populations. The sample was systematically drawn from lists of farmers maintained by the Agricultural Stabilization and Conservation Service office in each county of the study area. Farm operators on these lists and earning more than $\$ 1,000$ gross farm income in 1974 were the population of interest. Marginally active farmers were screened out of the sample in the interview process. A total of 345 farm operators were interviewed in 1975. This sampling design resulted in approximately the same percent of the farm operator population in each county being interviewed. The sample of 345 represents 9.4 percent of the total population of farmers, and a slightly larger percentage of the farm operator population with gross farm incomes of $\$ 1,000$ or more. The interviews were face-to-face and elicited a wide range of information (M. A. Brown, 1977). Only data concerning these farm operators' locations, farming activities, and adoption or nonadoption of innovations A through $\mathrm{D}$ are analyzed here.

The four populations are the known adopters of the four innovations as listed on diffusion agency records. These records provided locations of adopters and dates of adoption for all four innovations. ${ }^{1}$ Since some farm operators have adopted more than one of the innovations, the four populations are not mutually exclusive. Similarly, since some farmers in the random sample have adopted one or more of the innovations, the populations and sample are not mutually exclusive.

\section{THE ANALYTIC PROCEDURE}

The spatial distribution of the random sample provides a basis for characterizing the spatial distributions of "potential adopters." A potential adopter is defined as a farm operator whose farming activities are appropriate for the innovation in question. ${ }^{2}$ Four subsamples of potential adopters, one for each innovation, was derived from the random sample. These subsamples overlap, since any one farmer may undertake activities suitable to two or more innovations. (For instance, if a farm operator has five or more beef cattle, then he is a potential adopter for both pro-las and the Ohio Production Testing Program.)

The hypotheses are tested through cartographic and quadrat analysis of the subsamples of potential adopters and the four populations of adopters. The cartographic analysis examines a contour map for each diffusion process, on which areas of nonadoption and adoption (by time period) are identified.

The study area was divided into squares for the quadrat analysis. Only quadrats located fully inside the study area are included in the analysis. Since the study area is irregularly shaped, and the quadrats are square, some of the potential adopters and adopters fall outside of the quadrats. The number of these varies by quadrat size, tending to be larger, the larger the quadrat. These quadrats are used to analyze the distribution of each of the subsamples of potential adopters, and each of the populations of adopters. 
The following paragraphs describe the quadrat analyses as applied to the populations of adopters. The number of adopters in each quadrat $\left(\mathrm{x}_{\mathrm{i}}\right)$, the mean number of adopters per quadrat $(\mathrm{m})$, and the variance around this mean (v) were determined. An R-statistic was calculated as the ratio of the variance to the mean (v/m). An R-ratio of 1.0 is consistent with a Poisson process, since one property of a Poisson generated distribution is that the variance about the mean is equal to the mean. $\mathrm{R}$-statistics greater than 1.0 indicate a tendency toward spatial clustering, and values less than 1.0 indicate a tendency toward spatial uniformity (Rogers, 1969a, 1969b, 1974).

Distributions generated by Poisson processes are considered random, being based on the following assumptions: (a) $\mathrm{n}$ adopters are placed in a region where each possible location for an adopter is equally likely to be chosen; and (b) the location of each adopter is independent of any other adopter (Getis and Boots, 1979, p. 18). Two tests are employed to assess the validity of a Poisson process as the generator of each spatial distribution. The R-ratio is tested by comparing $\mathrm{v}$ and $\mathrm{m}$ using a $\mathrm{t}$-test with standard error $\sqrt{[2 /(n-1)]}$ and $n-1$ degrees of freedom, where $n$ is the number of quadrats and

$$
\mathrm{t}=[(\mathrm{v} / \mathrm{m})-1.0] / \sqrt{[2 /(\mathrm{n}-1)]} .
$$

Positive values indicate clusteredness, while negative values indicate evenness (Rogers, 1974, p. 6). The second test compares each observed frequency distribution of number of points per quadrat with the frequency distribution expected for a Poisson model. The expected frequency is:

$$
\mathrm{P}(\mathrm{x} ; \mathrm{m})=\left(\mathrm{e}^{-\mathrm{m}} \mathrm{m}^{\mathrm{x}}\right) / \mathrm{x} \text { ! for } \mathrm{x}=0,1,2, \ldots, \mathrm{N} .
$$

The value of $\mathrm{P}$ for a given $\mathrm{x}$ is the expected proportion of all occurrences per sample area with $\mathrm{x}$ points per quadrat. A chi-square test compares the observed and expected frequency distributions. Frequencies are aggregated to achieve expectations of five or more quadrats; degrees of freedom are the number of comparisons minus two.

Each observed distribution is also compared with one generated by a compound negative binomial process, and which creates a distribution more clustered than random. Compound models represent locational processes in which individuals have dissimilar propensities to adopt in different subareas of a region. The assumptions of a compound negative binomial process are that: (a) the frequency of the various densities of adopters in subareas is distributed as the gamma distribution; and (b) within each subarea adopters are located according to a Poisson process.

The expected frequency distribution resulting from a compound negative binomial model is estimated as:

$$
\begin{aligned}
& \mathrm{P}(0 ; \mathrm{m}, \mathrm{k})=1 /[(\mathrm{k}+\mathrm{m}) / \mathrm{k}]^{\mathrm{k}} \text { and } \\
& \mathrm{P}(\mathrm{x} ; \mathrm{m}, \mathrm{k})=[(\mathrm{k}+\mathrm{x}-1) / \mathrm{x}][\mathrm{m} /(\mathrm{k}+\mathrm{m})][\mathrm{P}(\mathrm{x}-1)] \text { for } \mathrm{x}=1,2, \ldots, \mathrm{N} \text {, }
\end{aligned}
$$


TABLE 1:

Quadrat Analysis of Four Samples of Potential Adopters

\begin{tabular}{|c|c|c|c|c|c|c|c|c|c|c|c|c|}
\hline \multirow[b]{2}{*}{ Number of Quadrats (n) } & \multicolumn{3}{|c|}{$\begin{array}{l}\text { Pro-Las } \\
\text { Cattle Feed(A) }\end{array}$} & \multicolumn{3}{|c|}{$\begin{array}{l}\text { Custom Blended } \\
\text { Fertilizer(B) }\end{array}$} & \multicolumn{3}{|c|}{$\begin{array}{c}\text { No-Till } \\
\text { Farming(C) }\end{array}$} & \multicolumn{3}{|c|}{$\begin{array}{l}\text { Ohio Production } \\
\text { Testing Program(D) }\end{array}$} \\
\hline & 71 & 176 & $311^{*}$ & 71 & 176 & $311^{*}$ & 71 & 176 & $311^{*}$ & 71 & 176 & $311^{*}$ \\
\hline $\begin{array}{l}\text { Number of Potential } \\
\text { Adopters in } n \text { Quadrats }(\mathrm{N})\end{array}$ & 286 & 304 & 309 & 282 & 301 & 304 & 226 & 241 & 243 & 251 & 263 & 271 \\
\hline \multicolumn{13}{|c|}{ Observed Versus Poisson Distribution: } \\
\hline $\begin{array}{l}\text { Mean Number of Potential } \\
\text { Adopters per Quadrat } \\
(\mathrm{m}=\mathrm{N} / \mathrm{n})\end{array}$ & 4.03 & 1.73 & .99 & 3.99 & 1.71 & .98 & 3.18 & 1.37 & .78 & 3.54 & 1.49 & .87 \\
\hline 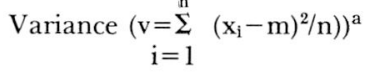 & 7.72 & 2.29 & 1.20 & 7.90 & 2.27 & 1.14 & 5.98 & 1.89 & .92 & 5.74 & 1.88 & 1.00 \\
\hline R-Statistic (v/m) & 1.92 & 1.33 & 1.20 & 1.98 & 1.33 & 1.17 & 1.88 & 1.38 & 1.17 & 1.62 & 1.26 & 1.15 \\
\hline $\begin{array}{l}\text { t-test } \\
\text { (level of significance) }\end{array}$ & $\begin{array}{l}5.42 \\
(.001)\end{array}$ & $\begin{array}{l}3.04 \\
(.01)\end{array}$ & $\begin{array}{l}2.54 \\
(.05)\end{array}$ & $\begin{array}{c}5.81 \\
(.001)\end{array}$ & $\begin{array}{l}3.08 \\
(.01)\end{array}$ & $\begin{array}{l}2.08 \\
(.05)\end{array}$ & $\begin{array}{c}5.20 \\
(.001)\end{array}$ & $\begin{array}{c}3.57 \\
(.001)\end{array}$ & $\begin{array}{l}2.16 \\
(.05)\end{array}$ & $\begin{array}{c}3.69 \\
(.001)\end{array}$ & $\begin{array}{l}2.38 \\
(.05)\end{array}$ & $\begin{array}{l}1.83 \\
\text { (n.s.) }\end{array}$ \\
\hline $\begin{array}{l}\mathrm{X}^{2} \text { test } \\
\text { (level of significance) }\end{array}$ & $\begin{array}{c}28.8 \\
(.001)\end{array}$ & $\begin{array}{c}8.6 \\
(\text { n.s. })\end{array}$ & $\begin{array}{c}4.0 \\
(\mathrm{n} . \mathrm{s} .)\end{array}$ & $\begin{array}{c}21.4 \\
(.001)\end{array}$ & $\begin{array}{c}8.1 \\
(\text { n.s. })\end{array}$ & $\begin{array}{c}3.8 \\
\text { (n.s.) }\end{array}$ & $\begin{array}{l}10.8 \\
\text { (n.s.) }\end{array}$ & $\begin{array}{c}3.0 \\
(\text { n.s. })\end{array}$ & $\begin{array}{c}6.4 \\
(\text { n.s.) }\end{array}$ & $\begin{array}{l}17.6 \\
(.01)\end{array}$ & $\begin{array}{c}4.8 \\
\text { (n.s.) }\end{array}$ & $\begin{array}{c}3.9 \\
\text { (n.s.) }\end{array}$ \\
\hline \multicolumn{13}{|c|}{$\frac{\text { Observed Versus Compound }}{\underline{\text { Negative Binomial Distribution: }}}$} \\
\hline $\mathrm{K}$-statistic & 4.40 & 5.31 & 4.87 & 4.06 & 5.19 & 5.84 & 3.62 & 3.59 & 4.51 & 5.66 & 5.87 & 5.93 \\
\hline $\begin{array}{l}\chi^{2} \text { test } \\
\quad \text { (level of significance) }\end{array}$ & $\begin{array}{c}8.2 \\
\text { (n.s.) }\end{array}$ & $\begin{array}{l}3.4 \\
\text { (n.s.) }\end{array}$ & $\begin{array}{r}.5 \\
\text { (n.s.) }\end{array}$ & $\begin{array}{c}6.3 \\
\text { (n.s.) }\end{array}$ & $\begin{array}{c}5.2 \\
(\text { n.s. })\end{array}$ & $\begin{array}{c}.2 \\
(\text { (n.s.) }\end{array}$ & $\begin{array}{c}7.2 \\
\text { (n.s.) }\end{array}$ & $\begin{array}{c}1.6 \\
\text { (n.s.) }\end{array}$ & $\begin{array}{l}4.3 \\
\text { (n.s.) }\end{array}$ & $\begin{array}{l}10.1 \\
\text { (n.s.) }\end{array}$ & $\begin{array}{c}.9 \\
\text { (n.s.) }\end{array}$ & $\begin{array}{c}1.5 \\
\text { (n.s.) }\end{array}$ \\
\hline
\end{tabular}

*indicates the number of quadrats most appropriate to the number of potential adopters.

$a_{x_{4}}$ is the number of adopters in quadrat $i$. 
where $\mathrm{k}$ is estimated as:

$$
\mathrm{K}=\mathrm{m} \%(\mathrm{v}-\mathrm{m}) \text {. }
$$

$\mathrm{K}$ is a measure of the degree of clustering associated with the contagious process. Its exact values range from zero to infinity, with zero indicating an extremely clustered distribution, and infinity indicating a Poisson or random distribution (Thomas, 1980, p. 20). Chi-square tests are used to compare this expected distribution with observed distributions (Getis and Boots, 1978, pp. 50-3).

Separate analyses are completed for three different quadrat sizes. One analysis employs 311 quadrats, each being 5 square miles in area; a second employs 176 quadrats, each 9 square miles in area; and a third uses 71 quadrats, each 19 square miles in area. Three analyses are undertaken because of the tendency for large quadrats to yield high variances and hence to indicate clusteredness, and for small quadrats to yield small variances and hence to indicate randomness. Curtis and McIntosh (1950) suggest the general rule that the appropriate quadrat size is approximately twice the size of the mean area per point. This paper places particular emphasis upon the results of the quadrat analyses which come closest to meeting this criterion.

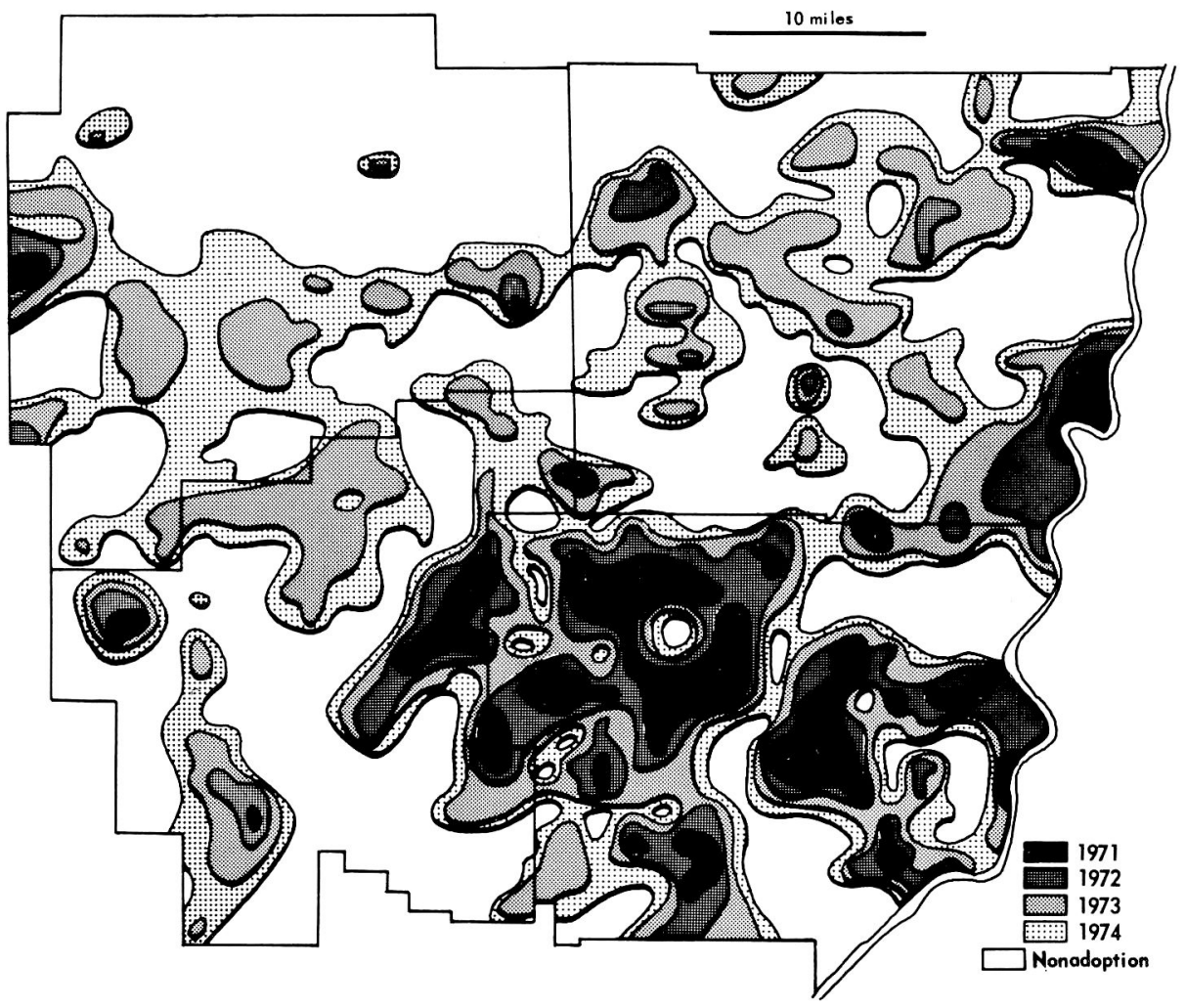

Figure 2a: The Diffusion of Pro-las Liquid Cattle Feed 
TABLE 2.

Quadrat Analysis of Adopters of Pro-las

\begin{tabular}{|c|c|c|c|c|c|c|c|c|c|c|c|c|}
\hline \multirow[b]{2}{*}{ Number of Quadrats } & \multicolumn{2}{|c|}{$\begin{array}{c}1 / 1 / 72 \\
(\mathrm{~N}=92)\end{array}$} & \multirow[b]{2}{*}{311} & \multicolumn{2}{|c|}{$\begin{array}{c}1 / 1 / 73 \\
(\mathrm{~N}=141)\end{array}$} & \multirow[b]{2}{*}{$311^{*}$} & \multicolumn{2}{|c|}{$\begin{array}{c}1 / 1 / 74 \\
(\mathrm{~N}=246)\end{array}$} & \multirow[b]{2}{*}{$311^{*}$} & \multicolumn{2}{|c|}{$\begin{array}{c}7 / 1 / 74 \\
(\mathrm{~N}=292) \\
\end{array}$} & \multirow[b]{2}{*}{$311 *$} \\
\hline & 71 & $176^{*}$ & & 71 & 176 & & 71 & 176 & & 71 & 176 & \\
\hline \multicolumn{13}{|c|}{ Observed Versus Poisson: } \\
\hline R-Statistic & 6.6 & 3.8 & 2.8 & 6.3 & 3.6 & 2.7 & 4.5 & 1.8 & 2.2 & 4.4 & 1.8 & 2.1 \\
\hline t-test & .001 & .001 & .001 & .001 & .001 & .001 & .001 & .001 & .001 & .001 & .001 & .001 \\
\hline$\chi^{2}$ test & .001 & .001 & .001 & .001 & .001 & .001 & .001 & .001 & .001 & .001 & .001 & .001 \\
\hline \multicolumn{13}{|c|}{$\frac{\text { Observed Versus Compound }}{\underline{\text { Negative Binomial: }}}$} \\
\hline K-Statistic & .21 & .17 & .15 & .33 & .26 & .25 & .86 & .69 & .60 & 1.05 & .80 & .73 \\
\hline$\chi^{2}$ test & n.s. & n.s. & n.s. & n.s. & n.s. & n.s. & n.s. & n.s. & n.s. & n.s. & n.s. & n.s. \\
\hline
\end{tabular}

*indicates the number of quadrats most appropriate to the number of adopters.

TABLE 3:

Quadrat Analysis of Adopters of Custom Blended Fertilizer

\begin{tabular}{|c|c|c|c|c|c|c|c|c|c|c|c|c|}
\hline \multirow[b]{2}{*}{ Number of Quadrats } & \multicolumn{2}{|c|}{$\begin{array}{c}1 / 1 / 72 \\
(\mathrm{~N}=125)\end{array}$} & \multirow[b]{2}{*}{311} & \multicolumn{2}{|c|}{$\begin{array}{c}1 / 1 / 73 \\
(\mathrm{~N}=222)\end{array}$} & \multirow[b]{2}{*}{$311^{*}$} & \multicolumn{2}{|c|}{$\begin{array}{c}1 / 1 / 74 \\
(\mathrm{~N}=269)\end{array}$} & \multirow[b]{2}{*}{$311 *$} & \multicolumn{2}{|c|}{$\begin{array}{c}7 / 1 / 74 \\
(\mathrm{~N}=322) \\
\end{array}$} & \multirow[b]{2}{*}{$311 *$} \\
\hline & 71 & $176^{*}$ & & 71 & 176 & & 71 & 176 & & 71 & 176 & \\
\hline \multicolumn{13}{|c|}{ Observed Versus Poisson: } \\
\hline R-Statistic & 3.5 & 2.2 & 1.7 & 3.7 & 2.6 & 1.8 & 4.2 & 2.8 & 2.0 & 4.7 & 3.2 & 2.1 \\
\hline t-test & .001 & .001 & .001 & .001 & .001 & .001 & .001 & .001 & .001 & .001 & .001 & .001 \\
\hline$\chi^{2}$ test & .001 & .001 & .01 & .001 & .001 & .001 & .001 & .001 & .001 & .001 & .001 & .001 \\
\hline \multicolumn{13}{|c|}{$\frac{\text { Observed Versus Compound }}{\underline{\text { Negative Binomial: }}}$} \\
\hline K-Statistic & .64 & .54 & .52 & 1.06 & .71 & .84 & 1.11 & .78 & .80 & 1.13 & .78 & .85 \\
\hline$\chi^{2}$ test & n.s. & n.s. & n.s. & n.s. & n.s. & n.s. & n.s. & n.s. & n.s. & n.s. & n.s. & n.s. \\
\hline
\end{tabular}

*indicates the number of quadrats most appropriate to the number of adopters. 


\section{THE RESULTS}

The samples of potential adopters are distributed as in Table 1. The quadrat analyses using 311 quadrats are the most appropriate to these sample sizes. Using a significance level of .05 and 311 quadrats, the R-statistics for innovations A, B, and C are significantly greater than 1.0, while the R-statistic for $\mathrm{D}$ is not. Employing a level of significance of .001, however, none of the R-statistics are greater than 1.0. The chi-square tests suggest that none of the distributions of potential adopters is significantly different from ones generated by either Poisson or compound negative binomial processes. The K-values indicate the greatest degree of clustering for $\mathrm{C}$ and the least for $\mathrm{D}$. These results suggest a slightly clustered distribution of potential adopters for innovations $\mathrm{A}, \mathrm{B}$, and $\mathrm{C}$, and a random distribution of potential adopters for innovation $\mathrm{D}$.

Table 1 also illustrates the tendency for smaller quadrats (and for smaller values of $\mathrm{m}$ ) to reduce evidence of clustering. For each of the four samples of potential adopters, the $\mathrm{R}$-statistic is largest with 71 quadrats and smallest with 311 .

Figure 2a portrays the spatial diffusion of A adopters and suggests that the density of adopters decreases with distance from Bethesda and

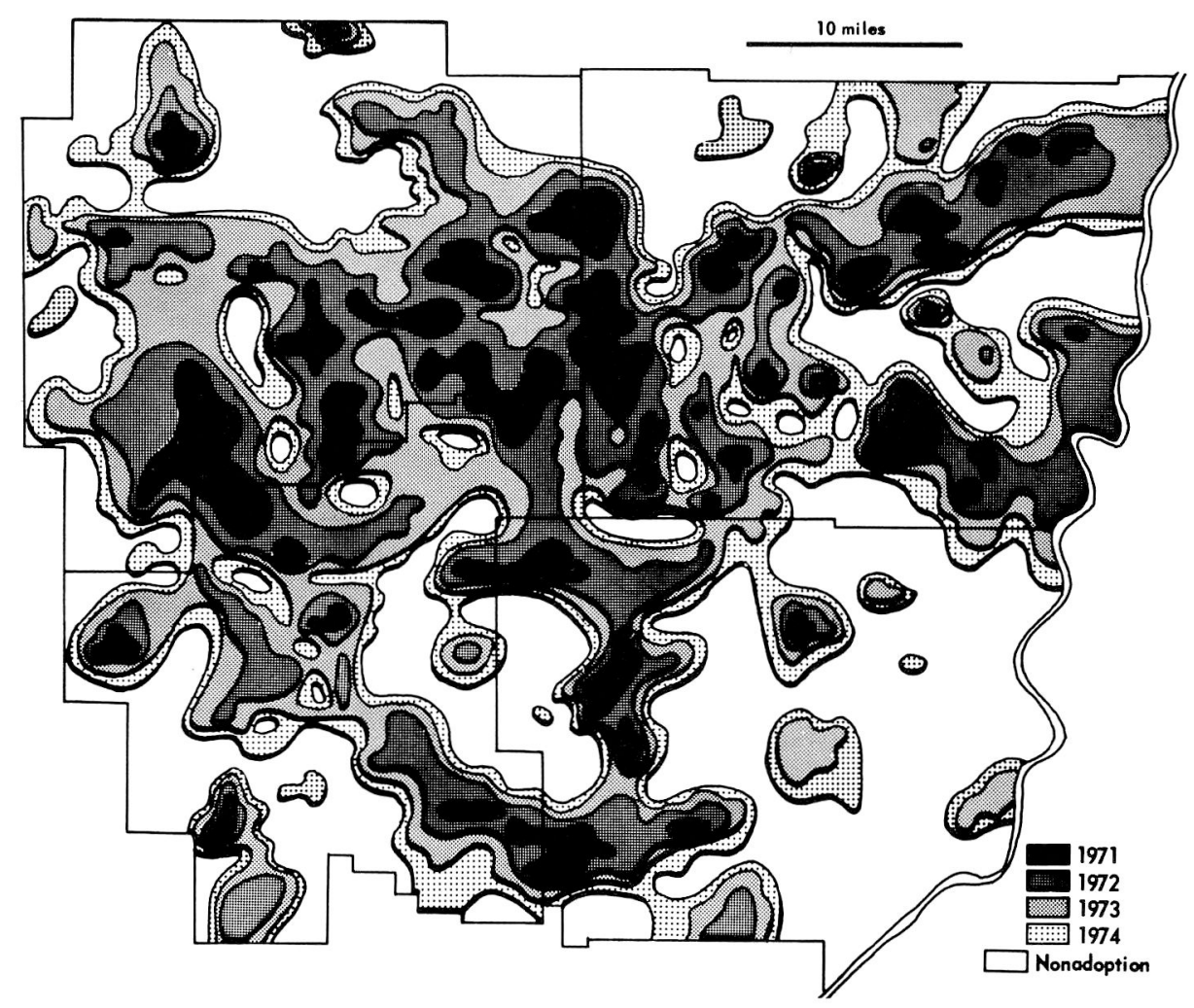

Figure 2b: The Diffusion of Custom Blended Fertilizer 
TABLE 4:

Quadrat Analysis of Adopters of No-Till Farming

\begin{tabular}{|c|c|c|c|c|c|c|c|c|c|c|c|c|}
\hline \multirow[b]{2}{*}{ Number of Quadrats } & \multicolumn{2}{|c|}{$\begin{array}{c}1 / 1 / 72 \\
(\mathrm{~N}=78)\end{array}$} & \multicolumn{4}{|c|}{$\begin{array}{c}1 / 1 / 73 \\
(N=114)\end{array}$} & \multicolumn{2}{|c|}{$\begin{array}{c}1 / 1 / 74 \\
(N=144)\end{array}$} & \multicolumn{4}{|c|}{$\begin{array}{c}1 / 1 / 75 \\
(\mathrm{~N}=194)\end{array}$} \\
\hline & 71 & $176^{*}$ & 311 & 71 & $176 *$ & 311 & 71 & 176 & $311 *$ & 71 & 176 & $311^{*}$ \\
\hline \multicolumn{13}{|c|}{ Observed Versus Poisson: } \\
\hline R-Statistic & 1.8 & 1.3 & 1.3 & 2.8 & 1.9 & 1.6 & 3.4 & 2.2 & 1.7 & 3.4 & 2.2 & 1.7 \\
\hline t-test & .001 & .001 & .001 & .001 & .001 & .001 & .001 & .001 & .001 & .001 & .001 & .001 \\
\hline$\chi^{2}$ test & n.s. & .05 & .05 & .001 & .05 & .001 & .001 & .001 & .001 & .001 & .001 & .001 \\
\hline \multicolumn{13}{|c|}{$\frac{\text { Observed Versus Compound }}{\text { Negative Binomial: }}$} \\
\hline K-Statistic & 1.04 & 1.20 & .74 & .72 & .60 & .51 & .69 & .57 & .53 & .88 & .76 & .69 \\
\hline$\chi^{2}$ test & n.s. & - & - & n.s. & n.s. & n.s. & n.s. & n.s. & n.s. & n.s. & n.s. & n.s. \\
\hline
\end{tabular}

*Indicates the number of quadrats most appropriate to the number of adopters. - - indicates that there are zero degrees of freedom; hence, no test is performed. 


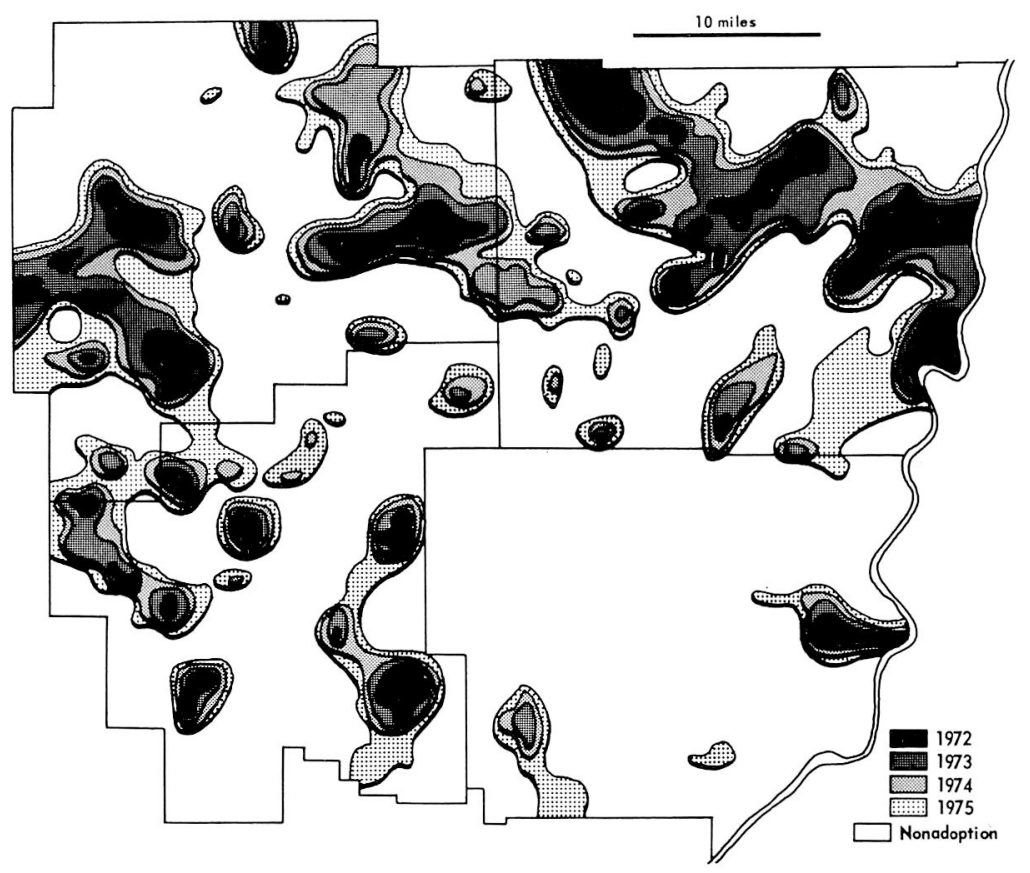

Figure 2c: The Diffusion of No Till Farming

Woodsfield, the locations of the two points of distribution. Over time, however, the pattern appears to expand outward in a wavelike fashion, mirroring the Farm Bureau's intention to promote the product in successive counties as delivery routes were established. The clustered distribution of $\mathrm{A}$ adopters is supported by a quadrat analysis of adopters in the years 1971 to 1974 . In each time period, the t- and chi-square tests indicate a significantly more clustered than Poisson distribution, and one which is not significantly different from a compound negative binomial distribution (Table 2). Further, the R-statistics decrease and the K-statistics increase over the four time periods, indicating a markedly clustered distribution overall, but one which becomes less so over time. The conclusion of decreased clusteredness is particularly significant since the increased number of adopters in later time periods causes a statistical bias toward increased variance and larger R-statistics, suggesting increased clusteredness.

The spatial distribution of adopters of $\mathrm{B}$ also is clustered around a point of distribution (Figure $2 \mathrm{~b}$ ). However, there appears to be a scattering of early adopters in peripheral areas. It therefore appears that earlier adopters were more dispersed throughout the study area than later adopters, and that the clustering noted above increased through time. These observations are supported by a quadrat analysis of the distribution of adopters in the years 1971 through 1974 (Table 3 ). As with innovation A, the $\mathrm{t}$ - and chi-square tests indicate a significantly more clustered than Poisson dis- 
TABLE 5:

Quadrat Analysis of Adopters of the

Ohio Production Testing Program

\begin{tabular}{|c|c|c|c|}
\hline \multirow[b]{2}{*}{ Number of Quadrats } & \multicolumn{2}{|c|}{$\begin{array}{l}1 / 1 / 75 \\
(\mathrm{~N}=71)\end{array}$} & \multirow[b]{2}{*}{311} \\
\hline & 71 & $176^{*}$ & \\
\hline \multicolumn{4}{|c|}{ Observed Versus Poisson: } \\
\hline R-Statistic & 1.9 & 1.4 & 1.6 \\
\hline t-test & .001 & .001 & .001 \\
\hline$\chi^{2}$ test & n.s. & n.s. & .01 \\
\hline \multicolumn{4}{|c|}{$\frac{\text { Observed Versus Compound }}{\text { Negative Binomial: }}$} \\
\hline $\mathrm{K}$-Statistic & .98 & .81 & .32 \\
\hline$\chi^{2}$ test & n.s. & & - \\
\hline
\end{tabular}

*indicates the number of quadrats most appropriate to the number of adopters. - - indicates that there are zero degrees of freedom; hence, no test is performed.

tribution in each time period, and one which is not significantly different from a compound negative binomial distribution. Unlike innovation A, the R-statistics tend to increase across time periods, while the K-statistics have little pattern, indicating a slight trend toward greater clustering through time.

Thus, the contour maps and quadrat statistics support both Hypotheses 1 and 2. However, the increased clustering through time for B was unanticipated in Hypothesis 2. Perhaps this trend can be attributed to a growing awareness of the population of potential adopters concerning the tradeoff between transportation costs and benefits of adoption. It also accords with the general finding that innovators have relatively cost inelastic demand for new goods, making them less sensitive than later adopters to the cost of overcoming distance to the fertilizer blend plant.

Figure 2c and Table 4 suggest that the spatial distribution of $\mathrm{C}$ adopters from 1972 through 1975 develops from one that is random (or at least no more clustered than the potential adopters of C) to one composed of small, localized clusters of adopters spread throughout the study area. Further, there appears to be no spatial trend in the time these dispersed clusters were established. The R-statistics increase through time to values much larger than those for potential adopters, while the K-statistics are higher in 1972 than in any subsequent time period. Thus, there is a trend toward increased clustering of $\mathrm{C}$ adopters and a process which may be compound negative binomial, but is not Poisson.

The contour map of $\mathrm{D}$ adopters (Figure 2d) suggests an overall dispersed distribution of adopters from 1968 to 1975, with a few small 
localized clusters existing throughout. The quadrat analysis of adopters by 1975 suggests that the degree of clusteredness is only slightly greater than that for the random sample of potential adopters (Table 5). No quadrat analysis of earlier time periods was undertaken because of the small population of earlier adopters. Thus, Hypotheses 3 and 4 are both supported.

\section{CONCLUSIONS}

This paper discussed and empirically examined spatial diffusion aspects of marketing strategies. In general, it illustrated that the location of marketing agencies, infrastructure development, pricing, promotional communications, and market segmentation may have significant and varying effects upon spatial patterns of diffusion. In particular, it demonstrated that the infrastructure constrained/independent distinction has important spatial implications, and that its role will depend upon the nature of the other marketing strategies employed. Thus, the two infrastructure constrained innovations, A and B, showed marked clustering overall. centered on one or a few outlets and shifting through time in a manner coincident with the marketing mechanisms employed for each. In particular, adop-

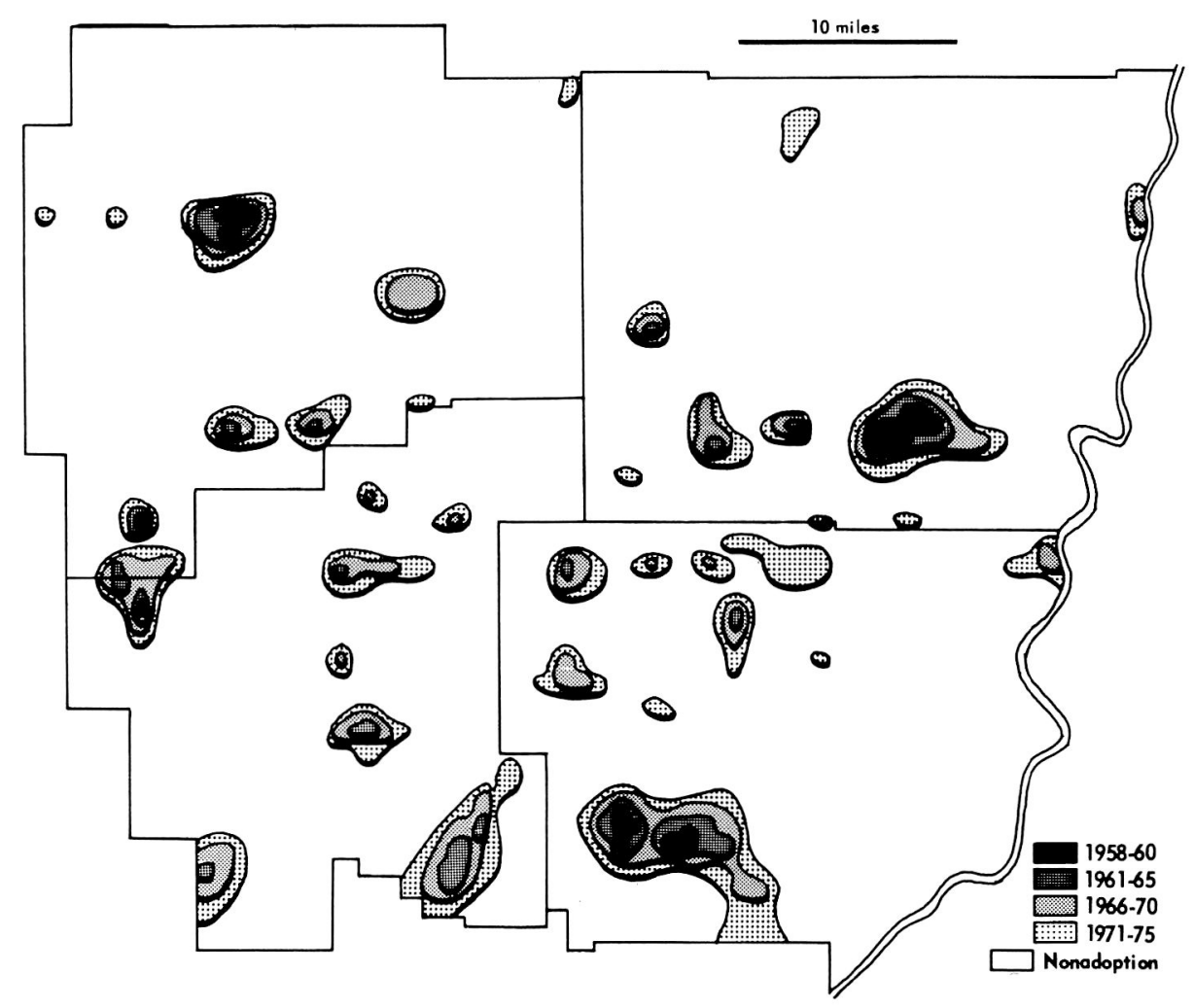

Figure 2d: The Diffusion of the Ohio Production Testing Program 
ters of A became more dispersed through time, concomitant with the development of a delivery system, a uniform delivered pricing scheme, and a spatially controlled communication campaign; adopters of B became less dispersed through time, possibly as the area-wide media campaign became offset by the increased recognition of, and sensitivity to, distancerelated delivery and pick-up costs. By contrast, the diffusion pattern for the infrastructure independent innovation, $\mathrm{D}$, and for the early stages of $\mathrm{C}$, were more dispersed. C and D provide evidence of how an area-wide diffusion process related to diffusion agency actions may operate jointly with a highly localized diffusion process to produce neighborhood effects and clusters of adoption. In general, then, the cartographic and quadrat analyses provide evidence that certain combinations of marketing mechanisms give rise to predictable spatial patterns.

\section{FOOTNOTES}

${ }^{1}$ Adopters of Pro-las and custom blended fertilizer were identified by customer lists obtained from the Belmont County Farm Bureau Cooperative. Date of adoption is the date of first purchase. Data on no till farming were provided by the Ohio Department of Agriculture, Division of Plant Industry. Date of adoption is the time the farm operator first applied for a permit to use paraquat, an herbicide that is an integral part of no till practices. The Ohio Cooperative Extension Service provided information on current users of the Ohio Production Testing Program, but was unable to supply in- formation for earlier adopters who are now inactive, or for date of adoption of current adopters.

${ }^{2}$ The subsample of potential adopters for Pro-las is defined as those randomly selected farm operators who have five or more beef cattle and/or sheep. For custom blended fertilizer it is those farm operators with at least five acres in crop produciton; for no-till farming it is those with at least five acres in corn production; and for the Ohio Production Testing Program it is those farmers with at least five beef and/or dairy cattle.

\section{REFERENCES}

Arndt, J. Word of Mouth Advertising. New York: Advertising Research Foundation, 1967.

Brown, L. A. "The Market and Infrastructure Context of Adoption: A Spatial Perspective on the Diffusion of Innovation," Economic Geography 51(1975), 185-216.

Brown, L. A. and Lentnek, B. "Innovation Diffusion in a Developing Economy: A Mesoscale View," Economic Development and Cultural Change, 21(1973), 274-292.

Brown, L.A., Malecki, E.J., Gross, S.R., Shrestha, M.N., and Semple, R.K. "The Diffusion of Cable Television in Ohio: A Case Study of Diffusion Agency Location Processes of the Polynuclear Type," Ecomomic Geography 50(1974), 285-299.

Brown, M.A. The Role of Diffusion Agencies in Innovation Diffusion: A Behavioral Approach. Ph.D. Dissertation, The Ohio State University, Department of Geography. Also in Studies of Diffusion of Innovation Discussion Paper Series, Department of Geography, The Ohio State University, 1977.

Brown, M.A. "A Typology of Suburbs and its Public Policy Implications," Urban Geography 2(1981), 288310.

Brown, M.A. and Brown, L.A. "The Diffusion of Bank Americard in a Rural Setting: Supply and Infrastructure Considerations," Proceedings of the Association of American Geographers, 8(1976), 74-78.

Coleman, J.S., Katz, E., and Menzel, H. "The Diffusion of an Innovation Among Physicians," Soctometry, 20(1959), 253-270.
Curtis, T.T. and McIntosh, R.R. "The Interrelations of Certain Analytic and Synthetic Phytosociological Characters," Ecology, 31(1950), 434-55.

Garst, R.D. "Innovation Diffusion Among the Gusii of Kenya,” Economic Geography, 50(1974), 300-312.

Getis, A. and Boots, B. Models of Spatial Processes. Cambridge: Cambridge University Press, 1978.

Hagerstrand, T. Innovation Diffusion as a Spatial Process. Chicago: University of Chicago Press, 1967.

Meyer, J.W.Diffusion of an American Montessori Education. Chicago: University of Chicago, Department of Geography, Research Paper Series, 1975.

Redlich, F. "Ideas, Their Migration in Space and Transmittal Over Time: A Systematic Treatment," Kyklos, 6(1953), 301-322.

Rogers, A. "Quadrat Analysis of Urban Dispersion: 1. Theoretical Techniques," Environment and Planning, 1(1969a), 47-80.

Rogers, A. "Quadrat Analysis of Urban Dispersion: 2. Case Studies of Urban Retail Systems," Environment and Planning, 1(1969b), 155-172.

Rogers, A. Statistical Analysis of Spatial Dispersion. New York: Academic Press, 1974.

Rogers, E.M. Diffusion of Innovations. New York: The Free Press of Glencoe, Inc., 1962.

Schwirian, K.P. (ed.). Comparative Urban Structure: Studies in the Ecology of Cities. Lexington, MA: D.C. Heath and Company, 1974. 
Seiling, R.R., Malecki, E.J., and Brown, L.A. "Infrastructure Growth and Adoption: The Diffusion of Cable Television Within a Community," Studies in the Diffusion of Innovation Discussion Paper Series, Department of Geography, The Ohio State University, 1976.

Thomas, R.W. An Introduction to Quadrat Analysis. Norwich, England: Geo Abstracts Ltd., University of East Anglia, 1977.
U.S. Bureau of the Census. Census of Agriculture: 1969, Ohio County Data. Washington: U.S. Government Printing Office, 1972.

U.S. Bureau of the Census. Census of Population: 1970, Characteristics of the Population, Ohio. Washington: U.S. Government Printing Office, 1973.

U.S. Office of Revenue Sharing. General Revenue Sharing State and Local Data Elements. Washington, D.C.: U.S. Bureau of the Treasury, 1976. 